\title{
Funcionário da educação básica: \\ a formação técnico-pedagógica
}

\author{
Basic Education Workers: \\ the technical-pedagogical formation
}

Oficial de la educación básica:

la formación técnico-pedagógica

\section{JOÃO ANTÔNIO CABRAL DE MONLEVADE*}

Universidade Federal do Mato Grosso, Cuiabá- MT, Brasil.

\begin{abstract}
RESUMO: Proponho neste artigo reunir dados legais e históricos sobre os funcionários da educação básica e sobre sua formação profissional, bem como desenvolver algumas reflexões sobre o seu papel na educação brasileira, de 1550 até hoje, e sobre as perspectivas atuais de sua valorização, no que respeita à formação, no contexto da luta sindical. Além de informações objetivas de leis, normas e números, socorro-me da experiência pessoal como educador e dirigente sindical no Sintep/MT e na CNTE.
\end{abstract}

Palavras-chave: Funcionário da educação básica. Formação profissional. Formação técnica pedagógica.

\begin{abstract}
I propose in this article to gather legal and historical data about basic education employees and their professional formation, as well as to develop some reflections about their role in Brazilian education, from 1550 until today, and about the current perspectives of its valorization, in regards training in the context of the trade union struggle. In addition to objective information on laws, standards and numbers, I draw on personal experience as an educator and union leader at Sintep / MT and CNTE.
\end{abstract}

* Sociólogo e educador. Doutor em Educação pela Universidade Estadual de Campinas. Professor aposentado da Universidade Federal de Mato Grosso e consultor legislativo aposentado do Senado Federal. Ex-dirigente da Confederação dos Professores do Brasil (CPB, atual CNTE), foi membro do Conselho Nacional de Educação (1996-2000). E-mail: <professormonlevade@gmail.com>. 
Keywords: Basic education worker. Professional qualification. Pedagogical technical training.

RESUMEN: Propongo en este artículo recopilar datos legales e históricos sobre los oficiales de la educación básica y su formación profesional, bien como desarrollar algunas reflexiones sobre su papel en la educación brasileña, desde 1550 hasta hoy, y sobre las perspectivas actuales de su valorización, con respecto a la formación en el contexto de la lucha sindical. Además de informaciones objetivas sobre leyes, regulaciones y números, utilizo la experiencia personal como educador y líder sindical en Sintep/MT y CNTE.

Palabras clave: Oficial de educación básica. Formación profesional. Formación técnico-pedagógica.

\section{Introdução}

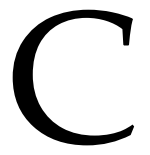

omecemos esclarecendo conceitos...

Por funcionários da educação básica entendemos o que define o Art. 61 da Lei n 9394, de 1996, que fixa as Diretrizes e Bases da Educação Nacional (LDB), ao discriminar as categorias consideradas "profissionais da educação", a teor da Lei 12.014, de 2009.

Literalmente:

\footnotetext{
Consideram-se profissionais da educação escolar básica os que, nela estando em efetivo exercício e tendo sido formados em cursos reconhecidos, são:

I - professores habilitados em nível médio e superior para a docência na educação infantil e nos ensinos fundamental e médio;

II - trabalhadores em educação portadores de diploma de pedagogia, com habilitação em administração, planejamento, supervisão, inspeção e orientação educacional, bem como com títulos de mestrado ou doutorado nas mesmas áreas;

III - trabalhadores em educação, portadores de diploma de curso técnico ou superior em área pedagógica ou afim.
}

Por que não se define os funcionários não-docentes como tais, ou seja, como o conjunto de trabalhadores da educação em funções e espaços que não os de "sala de aula"? Primeiro, porque os pedagogos da categoria II também atuam fora das salas de aula e são "funcionários" por princípio e pela filiação a órgãos públicos. Segundo, porque o movimento que levou à modificação do Art.61 - que não definia quem eram os "profissionais da educação" a que se referiam o Art. 206 da Constituição e o título da seção da 
LDB - era pautado pela convicção de que não se deve caracterizar uma categoria pelo que ela não é - no caso, "docente".

Este artigo tem por finalidade valorizar academicamente a Categoria III. Na história da educação eles, os funcionários, já estão presentes desde a primeira escola - o Colégio dos Meninos de Jesus, fundado pelos jesuítas em Salvador em 1550. E na atual geografia da educação escolar, a Categoria III é a mais numerosa nas escolas básicas públicas: 2,1 milhões de trabalhadores, ao lado de 1,9 milhão de professores(as) e de duzentos mil pedagogos, segundo estimativas confiáveis derivadas do Censo Escolar de 2017.

Ainda como introdução, percebamos que a definição de profissionais da educação inclui, nas três categorias, algum vínculo com sua formação profissional. Este fato justifica a centralidade dos processos formativos no desenvolvimento do presente texto. É em virtude de uma formação específica que a expressão genérica "trabalhadores da educação" se especifica nas três categorias de "profissionais da educação". Atentemos: se os sindicatos lutam pela valorização dos "trabalhadores em educação" - a começar da Confederação Nacional dos Trabalhadores em Educação - já a Constituição e a LDB são explícitas em valorizá-los como "profissionais da educação".

\section{Um pouco de história}

Desde a implantação dos 17 colégios jesuíticos e das centenas de escolas de primeiras letras confiadas às congregações católicas no Brasil-Colônia, foi sempre uma presença constante a destes educadores nas mais variadas funções - o que fez possível seu inquestionável sucesso civilizatório junto às populações que cresciam e se miscigenavam no Brasil. Concretamente: o fato de os maiores educandários serem "internatos" gerou a necessidade de dezenas de funções não docentes, todas ocupadas por educadores do sexo masculino, aptos a conviverem e se relacionarem com estudantes também meninos e rapazes. A obra de Serafim Leite - História da Companhia de Jesus no Brasil - é pródiga em enumerar e descrever estas funções: cozinheiros, enfermeiros, sacristães, bibliotecários, escriturários, pintores, ferreiros, arquitetos, administradores de fazendas, alfaiates, marceneiros e até pilotos de navios. O Regimento do Seminário de Olinda, escrito em 1800 pelo Bispo Azeredo Coutinho, como descreve Gilberto Luís Alves na obra biográfica publicada pelo MEC, é ainda mais pródigo na previsão de funções "oficiais" as mais diversas, além das citadas acima: porteiro, refeitoreiro e até barbeiro.

E não nos esqueçamos: desde 1551, os jesuítas, que defendiam a liberdade dos índios, lançaram mão de escravos para trabalhar nos maiores colégios do litoral. Os primeiros deles, como relata Serafim Leite, foram escravos pescadores, que garantiam as proteínas na alimentação dos estudantes, e depois outros “servidores", como aguadeiros, hortelãos 
e vaqueiros, em variados espaços como os quintais, chácaras e fazendas que sustentavam suas escolas, elementares e secundárias.

A prática de suporte material das atividades dos mestres subsistiu depois da expulsão dos jesuítas em 1759, inclusive nas Aulas Régias que o Marquês de Pombal oficializou, em 1772, como pretensa "substituição" da concessão que os reis de Portugal tinham feito à Companhia de Jesus e tinham estendido a carmelitas, beneditinos, franciscanos e religiosos de outras Ordens, durante os séculos XVI, XVII e XVIII.

Digna de nota e de reflexão econômica e antropológica é a missão educativa do irmão Vicente Rodrigues, ferreiro no Colégio da Bahia, feita por Manoel da Nóbrega, na primeira obra literária escrita no Brasil: Diálogos sobre a Conversão dos Gentios, de 1556, ainda quando ele era reitor daquele Colégio e provincial dos jesuítas. No processo de aculturação dos indígenas, da era da pedra polida à sociedade dos metais, Nóbrega dialoga com o irmão Rodrigues chamando-lhe a atenção de que, "batendo o martelo na bigorna e moldando facões, machados e anzóis" convertia mais os gentios à cultura cristã do que ele, com aulas e sermões. Esta arguta observação - onde conversão é sinônimo de educação - nos parece suficiente para firmar uma verdade: a de que a educação escolar está subordinada ao contexto socioeconômico mais amplo. Quanto mais as escolas contribuírem para a apropriação dos valores sociais pelas novas gerações, mais elas serão educadoras e cumpridoras de sua missão. E nesta tarefa, avulta e se agiganta o papel dos funcionários, não docentes, mas educadores.

Nossa atual sociedade, entretanto, é omissa, quando não injusta, em relação à importância dos(as) funcionários(as) que trabalham nas creches e pré-escolas, nas escolas de ensino fundamental e médio, nos cursos profissionais. Quantos porteiros, quantas merendeiras, quantos e quantas "não-docentes" têm sido mais decisivos para a oferta de escolaridade e mais educadores do que os próprios professores - estes últimos ainda fragilizados(as) por pouca formação, maus salários e de inadequadas condições de trabalho. Contudo, o que dizer da formação profissional dos atuais funcionários(as) na educação básica no Brasil?

Na verdade, a divisão social de trabalho, que se iniciou com os colégios religiosos coloniais e se estendeu até os dias de hoje nas instituições beneditinas, salesianas e maristas, bem como nas inúmeras escolas de congregações femininas e de educadores evangélicos, valorizou os docentes - que dominam o ensino da cultura letrada e científica - e desvalorizou os funcionários, que gerem e executam os trabalhos e espaços materiais das unidades escolares. Ainda recentemente, presenciei na Prelazia de Diamantino, Mato Grosso, entre 1969 e 1975, o papel que exerceu um irmão coadjutor jesuíta - Miguel Abib - como "arquiteto" sem diploma, projetando e construindo igrejas e escolas que possibilitaram a educação escolar de vários municípios. Procure-se uma escola, entre milhares no Brasil, cujo nome homenageie o de um funcionário, o de uma funcionária. 
Tão arraigadas estão a invisibilidade social e a subalternidade política dos funcionários que leis estaduais e municipais, em pleno século XXI, assumindo a gestão democrática, preveem a possibilidade de funcionários(as) serem diretores de escola, desde que, a exemplo dos professores, possuam diploma de curso superior. Ou seja: para estas leis, a competência em gestão e a liderança na escola nada contam: valem só os diplomas de habilitação formal, que funcionam como que muletas para eles se "encostarem" nos direitos dos professores, para muitos ainda pretensos educadores exclusivos.

Aprofundemos esta análise. Desde o período colonial, temos instituições formativas para os professores, disseminadas, a partir de 1835, por meio dos cursos "normais" para os do ensino primário e, no século $X X$, por meio das licenciaturas para os cursos secundários, para a formação dos educadores não docentes só havia a informalidade das "formações gerais", não reconhecidas para efeito de planos de carreira. Inclusive, ainda vivemos paradoxos: para um concurso de ingresso de merendeira, por exemplo, exige-se como título somente um certificado de escolaridade - ensino fundamental completo, em geral. Assim, eu, reconhecidamente inepto para esta tarefa, posso ser "aprovado" em lugar de uma profissional da área específica.

Por isto, a relevância da reflexão histórica sobre a questão da formação dos(as) funcionários(as). Alguém poderia nos apontar algum curso de formação profissional para eles e elas, previsto em Lei, até 1997? E hoje, bem entrados no século XXI, alguém conhece algum curso superior para formação de funcionários(as)? Abramos nossos olhos e mergulhemos na aventura - que pode nos levar a surpresas.

\section{Cursos técnicos e superiores de formação do funcionário}

Comecemos pelos cursos superiores. Desde 2009, o Instituto Federal de Educação, Ciência e Tecnologia do Acre (Ifac) oferta o Curso de Tecnologia em Processos Escolares, destinado a formação de funcionários de perfil "generalista" em nível superior. Um trabalho pioneiro, nascido de reivindicação do Sindicato dos Trabalhadores da Educação do Acre (Sinteac) ao qual se pode, dez anos depois, aplicar o adágio: “andorinha só não fez verão". Nenhuma universidade ou instituto, além do Ifac, ofereceu este curso superior, embora a demanda por eles crescesse a cada ano.

Antes de voltarmos aos cursos superiores, que prometem formação mais sólida para os funcionários se habilitarem como educadores da Categoria III, segundo o Art. 61 da LDB, focalizemos a evolução das ofertas de Cursos Técnicos de Formação de Funcionários em nível médio.

O primeiro "aconteceu" de forma pioneira por iniciativa da Secretaria Municipal de Educação de Cuiabá, como resposta a reivindicação do Sindicato de Trabalhadores do Ensino Público de Mato Grosso, Sintep/MT. Nossa fonte de dados, além de minha 
participação pessoal no projeto, é o depoimento de Carlos Maldonado e Nilca Machado de Matos, relatado no Caderno "Por uma política de valorização dos trabalhadores em educação Em cena, os funcionários de escola", editado pela Secretaria de Educação Básica do Ministério da Educação em setembro de 2004. Eles relatam que, desde 1997, "foram profissionalizados 490 funcionários, com outros 383 em turmas em andamento". Registrem-se aqui os nomes de Gilberto Fraga como gestor na Secretaria Municipal de Educação de Cuiabá e das professoras Zileide, Josenilde, Maria dos Anjos, Beatriz, Laldiceia e da funcionária Cilene como tutoras desta experiência que se pode considerar o "campo de provas" da proposta de formação das quatro habilidades a serem desenvolvidas posteriormente no Mato Grosso e oficializadas em seguida pelo Conselho Nacional de Educação.

Já o Projeto Arara Azul, segundo a mesma fonte, foi iniciativa da Secretaria Estadual de Educação de Mato Grosso, Seduc, de 1998 a 2004, e “habilitou 4.555 funcionários em 98\% dos municípios, como Técnicos em Administração Escolar, Técnicos em Nutrição Escolar, Técnicos em Multimeios Didáticos e Técnicos em Manutenção de Infra-estrutura Escolar". Os currículos destes cursos tinham sido "inspirados" pelas sugestões de João Monlevade, em seu livro, de 1995: Funcionários das Escolas Públicas: Educadores Profissionais ou Servidores Descartáveis, que, com a professora Marília Salomoni e outros educadores, havia participado da transformação da Associação Mato-grossense de Professores (AMP) em Associação Mato-grossense de Profissionais da Educação (AMPE), em 1987. Na falta de uma norma nacional, o Conselho Estadual de Educação de Mato Grosso, onde estava presente a professora Tania Pasqualini, diretora do Sintep, aprovou os planos de curso com os respectivos currículos como habilitações em gestão escolar, com ênfase nas quatro áreas acima citadas. Registre-se aqui a parceria entre o Governo Estadual, através da Seduc e dos esforços do Executivo e do Legislativo Mato-grossenses em implantar a Lei Orgânica dos Profissionais da Educação Básica(LOPEB), que previu as carreiras não só de professores como de técnicos e apoios administrativos escolares (TAE e AAE), desde que portadores dos diplomas nestas quatro habilitações.

Segundo artigo da professora Olga Freitas no Caderno acima referido, versões destes mesmos cursos foram ofertadas, com menor número de matrículas, no Acre e no Distrito Federal, com a mesma estrutura curricular, com carga horária total de $1.200 \mathrm{~h}$ : Bloco Pedagógico, com 300 h; Bloco Técnico, com 900 h, subdivididas em disciplinas técnicas comuns a todas as habilitações (120 h), disciplinas específicas de cada curso (480 h) e Prática Supervisionada de Trabalho (300 h).

No Acre e no Distrito Federal, a exemplo de Mato Grosso, estes cursos - na falta de norma legal - foram autorizados pelos respectivos Conselhos de Educação, em formatos que tomavam por base a habilitação técnica em gestão, com ênfase nas terminalidades das quatro áreas acima expostas.

No plano nacional, desde 2003, o MEC começou a se preocupar com a valorização dos funcionários da educação básica, financiando cursos de qualificação e outras ações 
nos estados e municípios que os solicitassem. Uma delas eram as iniciativas de avanço de escolaridade destes servidores - cerca de 70\% dos quais, à época, só possuíam certificação do antigo nível primário, ou seja, de quarta série do $1^{\circ}$ grau. Registre-se que em muitas regiões do Brasil houve uma acelerada contratação de merendeiras, vigias e agentes de conservação e limpeza, para viabilizar o funcionamento das escolas que se multiplicavam e reforçar os laços clientelísticos entre políticos e trabalhadores/eleitores, com salários irrisórios, muitas vezes aquém do mínimo nacional.

O grande passo adiante ocorreu em setembro de 2004, no Governo Lula e na gestão do ministro Fernando Haddad, quando a Secretaria de Educação Básica do MEC promoveu em Brasília o Seminário Nacional sobre a Política de Valorização dos Trabalhadores em Educação, que reuniu mais de 100 representantes do próprio Ministério, do Conselho Nacional de Secretários de Educação(Consed), da União Nacional de Dirigentes Municipais de Educação(Undime), e dos sindicatos filiados à CNTE. O evento durou três dias, sob a coordenação dos professores Francisco das Chagas Fernandes, Horácio Francisco dos Reis Filho e Arlindo Cavalcanti de Queiroz, todos da Secretaria de Educação Básica (SEB), do Ministério da Educação.

Além de palestras de especialistas na área, como do professor Márcio Baiocchi, assessor da senadora Fátima Cleide, de Rondônia - ela mesma funcionária de secretaria escolar - do deputado federal pelo MT, Carlos Abicalil, do professor João Monlevade, então consultor legislativo no Senado Federal, e da professora Olga Freitas, da rede pública do Distrito Federal, um dia inteiro foi dedicado a relatos das experiências de formação e outro a trabalho em grupos para sugerir estratégias para um Programa de Formação.

Como conclusão prática, o secretário da SEB, Francisco das Chagas, propôs a seu diretor Horácio Reis a criação e implantação de um Programa, que denominou informalmente de Profuncionário. Confiou então ao professor João Monlevade, ex-diretor da CNTE, a coordenação de um grupo de professores e pós-graduandos da UnB para a imediata concepção e detalhamento de um Projeto Piloto, bem como o desafio de produzir "módulos didáticos" de 39 disciplinas - pedagógicas e técnicas - para implantação do Programa no ano seguinte. Constituiu-se, assim, uma Coordenação Técnica envolvendo pessoas do MEC e da UnB - esta última a cargo do Centro de Educação a Distância (Cead) cujo coordenador era o professor doutor Bernardo Kipnis. Registre-se que os módulos técnicos específicos das quatro áreas foram confiados, respectivamente, a Francisco das Chagas Nascimento (Secretaria Escolar), Maria Abádia da Silva (Alimentação Escolar), João Monlevade (Infraestrutura Escolar) e Bernardo Kipnis (Multimeios Didáticos), os quais, por sua vez, escolheram especialistas ligados às disciplinas - a maioria deles docentes da UnB.

Para viabilizar institucionalmente o Profuncionário, o MEC fez consulta formal ao Conselho Nacional de Educação, com vistas a criar a 21ํㅗ́ Área de Formação Profissional em Nível Médio - o que aconteceu por Parecer do conselheiro Francisco Cordão e pela 
Resolução 05/2005 da Câmara de Educação Básica do mesmo CNE, que disciplinou as quatro habilitações por meio de proposta curricular de 1.200 horas, composta de seis disciplinas pedagógicas, três técnicas comuns e sete técnicas específicas, em modalidade semipresencial, com $80 \%$ da carga horária na modalidade à distância.

Em novembro de 2005, impressos já os seis Cadernos Pedagógicos, foram iniciados os cursos em Pernambuco, Piauí, Tocantins, Paraná e Mato Grosso do Sul. Em fins de 2006 somou-se o estado de Goiás a este Projeto Piloto e em 2007 ocorreu expansão para mais 12 estados. De fins de 2006 a 2008, a Coordenação do Projeto foi confiada a Sirlene Alves dos Santos, ela mesma funcionária contratada temporária pela Secretaria de Educação de Goiás. Sua gestão foi muito eficiente, mas ela não deixou de enfrentar no MEC a "estranheza" de colegas mestras e doutoras, que criticavam os chefes por terem confiado um cargo de DAS 4 a uma pessoa com simples certificado de ensino médio.

Em 2011, o Profuncionário teve sua execução transferida para a Secretaria de Educação Profissional e Tecnológica (Setec), que estendeu sua oferta aos recém implantados institutos federais de educação, ciência e tecnologia, com opção de certificação por algumas secretarias estaduais de educação, como havia ocorrido de 2007 a 2010.

O fato mais significativo destes anos sob a Setec foi a organização de um Grupo de Trabalho, constituído de "tutores senior", oriundos das secretarias de educação do MT, GO, DF, TO, PR, MS, RS e MG, com a participação ativa de alguns "escritores" de Cadernos das Disciplinas, como Maria Abádia da Silva, Dante Diniz Bessa, Regina Sucupira Pedroza e João Monlevade. Na Setec trabalhava uma equipe de coordenação, inclusive na atualização do material didático e na redação do Caderno de Orientações Gerais, sob a batuta num primeiro momento de Fernando Amorim (IFPR) e em período maior de Carlos Artur Areias (IFRJ) e de Cassandra Ribeiro Joye (IFCE).

\section{Quem é responsável pela formação do funcionário da educação?}

Recorramos mais uma vez à LDB:

Art. 62-A A formação dos profissionais a que se refere o inciso III do art. 61 far-se-á por meio de cursos de conteúdo técnico-pedagógico, em nível médio ou superior, incluindo habilitações tecnológicas.

Parágrafo único. Garantir-se-á formação continuada para os profissionais a que se refere o caput, no local de trabalho ou em instituições de educação básica e superior, incluindo cursos de educação profissional, cursos superiores de graduação plena ou tecnológicos e de pós-graduação.

Este artigo foi incluído na LDB pela Lei 12.796, de 2013, quando o Profuncionário estava em ascensão em termos de oferta e de aperfeiçoamento quanto à qualidade e à adaptação a novas normas legais. 
Em virtude de dispositivo constitucional, do Art. 211, os estados e o Distrito Federal são responsáveis pela oferta de cursos de ensino médio, incluídos os profissionais. Daí a prática, nas experiências dos anos 1990 e entre 2005 e 2011, de as secretarias estaduais terem oferecido e certificado os cursos técnicos. Com a criação dos institutos federais de educação, ciência e tecnologia, a mesma responsabilidade passou a ter um locus mais apropriado, pelo caráter técnico dos cursos de formação dos funcionários. Mudanças na LDB também atingiram a estrutura dos cursos técnicos, ou seja, dos cursos profissionais de nível médio: eles podem ser oferecidos de forma integrada, concomitante ou subsequente. Esta última, inclusive, na modalidade a distância, mais apropriada a cursos de formação continuada oferecidos a trabalhadores. Foi o que ocorreu com os cursos do Profuncionário. Como a lei garante também, para os que só tenham o ensino fundamental, a matrícula em cursos concomitantes, um bom número de funcionários nessas condições foi admitido a este tipo de oferta, com uma advertência: o diploma de técnico só seria concedido aos que, durante ou depois de terminadas as 1.500 hs de algum dos cursos técnicos, tivessem concluído também a etapa do ensino médio, seja num curso presencial, seja por um exame supletivo.

Alguém pode estranhar a mudança de carga horária, de 1.200 para 1.500 horas. Isto se deveu a Resolução do CNE sobre cursos profissionais que exigiram a contagem das 300 horas da Prática Supervisionada (equiparada aos estágios curriculares) além das 1.200 horas das disciplinas que compõem os cursos. A nova versão do Caderno de Orientações Gerais, bem como o da Orientação da Prática Supervisionada, implantou estas inovações, sem alterar a duração dos cursos - de 18 a 20 meses.

A grande questão que se colocava em 2013-2016 era a de que toda a oferta dos Cursos de Profissionalização em nível médio (os quatro técnicos e outros cuja oferta se planejava nas áreas de transporte de escolares, de cuidado das pessoas deficientes e de desenvolvimento infantil) se fazia como formação continuada na modalidade EaD.

Com exceção de experiência em Mato Grosso de oferta em Centros de Educação de Jovens e Adultos (Ceja), não temos conhecimento de nenhuma rede pública, de nenhuma escola de ensino médio pública ou privada que tivesse sido autorizada pelos respectivos conselhos estaduais a oferecer cursos técnicos integrados, concomitantes ou subsequentes como formação inicial de adolescentes e jovens que se destinassem a posterior ingresso na carreira da Categoria III dos profissionais da educação.

Este fato, a esta altura, é, no mínimo, de estranhar. Mesmo com as tendências de terceirização dos "serviços educacionais não docentes", mesmo com a legislação atualizada e as normas do CNE e do Decreto 8.752, de 9 de maio de 2016, que dispõe sobre a Política Nacional de Formação dos Profissionais da Educação Básica, em vigor até hoje, mesmo com o vasto "mercado" de postos de trabalho não-docentes nas escolas e nos órgãos dos sistemas de ensino, não ocorreu o atendimento em cursos técnicos para esta vasta demanda social - até mesmo nos institutos federais, muito envolvidos na oferta do Profuncionário. 
Talvez uma reflexão sobre o esforço dos sindicatos em reivindicar a oferta de cursos superiores - com avanços institucionais inegáveis que vamos registrar em seguida - ajude a contextualizar este aparente paradoxo.

O Ifac criou o Curso Superior de Tecnologia em Processos Escolares, com base no Catálogo da Semec/MEC. Entretanto, por pressão da CNTE e dos concluintes dos cursos técnicos do Profuncionário - quase cem mil à época - e em concordância com setores dos institutos federais interessados em ampliar a oferta de cursos superiores, o CNE, por meio da Câmara de Educação Superior, CES, resolveu colocar em pauta a definição de diretrizes curriculares para cursos superiores de tecnologia destinados à formação inicial e continuada de profissionais da educação básica da Categoria III, de acordo com o art. 61 da LDB em vigor no ano de 2014.

Instalou-se uma comissão para a realização de discussões e audiências públicas, presidida pelo conselheiro Erasto Fortes de Mendonça, sendo nomeado relator o conselheiro Luiz Fernandes Dourado. O seu relatório foi aprovado sob a forma do Parecer n⿳o 246, de 4 de maio de 2016, com o respectivo projeto de resolução. Vencidos os trâmites em tempo de urgência, diante da situação política que antevia o impeachment da presidente Dilma Rousseff, foi aprovada a Resolução, que, homologada pelo ministro Aloisio Mercadante Oliva, recebeu o no 02 , em 13 de maio de 2016.

Não nos parece ser o caso de expor e comentar os detalhes do Parecer e os dispositivos da Resolução - ambos dignos de uma atenta leitura. Basta aqui dar as informações que guiam, no geral, a oferta dos novos cursos, denominados agora como Cursos Superiores de Tecnologia em Educação e Processos de Trabalho em Alimentação Escolar, Infraestrutura Escolar, Secretaria Escolar e Multimeios Didáticos, com disciplinas de formação geral, pedagógica e técnica que, somadas a 300 horas de Estágio Supervisionado, totalizam 2.400 horas, no mínimo, em cada curso. De acordo com o $\S 4^{\underline{0}}$ do $\operatorname{art}^{\circ} 3^{\circ}$ e com o $\S 2^{\underline{0}}$ do art. 9º desta Resolução, "na perspectiva de que todos(as) os(as) funcionários(as) da educação básica sejam profissionalizados" o CNE acolherá, por meio de Resolução da CES, novas áreas de formação e atuação educativa além das quatro aqui discriminadas. As 1.700 horas mínimas das disciplinas são enriquecidas por 200 horas de práticas com elas articuladas e por mais 200 horas de "atividades teórico-práticas de aprofundamento em áreas de interesse dos estudantes", sob forma de seminários, atividades de pesquisa e extensão, mobilidade e intercâmbios previstos nos PPC, atividades de comunicação e expressão destinadas à efetiva capacidade de comunicar, interpretar e se integrar nos processos de trabalho das instituições da educação básica. Neste sentido, vários componentes curriculares dialogam com seus similares dos cursos de formação dos professores e dos pedagogos, o que permite interação entre os três cursos responsáveis pela formação dos profissionais da educação. Não só: contribuem para quebrar os "desníveis" atuais de status dos funcionários perante o prestígio social dos profissionais da educação das Categorias I e II. Em resumo, a Resolução, com seus considerandos de ordem filosófica 
e pedagógica e com os dispositivos de estrutura e funcionamento dos cursos se constitui como texto fundamental e obrigatório para orientar no presente e no futuro a formação dos funcionários, na expectativa que da presença e da qualidade de atuação deles nas escolas derivarão novas e significativas qualidades para toda a oferta de educação básica, em instituições públicas e privadas.

Concomitantemente, gestores e especialistas do MEC trabalharam de fevereiro a maio de 2016 na construção de um documento sobre as políticas nacionais de formação dos profissionais da educação básica. Ele se concretizou em 9 de maio de 2016, pelo Decreto 8.752, e, significativamente, em seu art.12, que elenca os programas e ações integrados e complementares de um Planejamento Estratégico Nacional, coloca como primeira, de 16 iniciativas, "a formação inicial e continuada em nível médio e superior para os trabalhadores da educação que atua na rede pública e nas escolas gratuitas da educação básica, em funções identificadas como da Categoria III dos profissionais da educação". Somada esta decisão política aos dispositivos da Meta 18 do Plano Nacional de Educação, garante-se institucionalmente a presença qualificada dos funcionários da educação nas políticas públicas do País e atualiza-se concretamente sua respectiva formação profissional. Alguma dúvida?

O que ocorreu, de maio de 2016 a dezembro de 2019, quando escrevemos este texto e vivemos mais de três anos pós Golpe de 2016?

Quanto ao Profuncionário, seus cursos em andamento não foram, obviamente, interrompidos. Celebraram-se em vários estados formaturas com concluintes dos quatro cursos, em especial oferecidos pelos institutos federais, com apoio financeiro da Setec/ MEC. Em compensação, não temos conhecimento de que, de 2017 em diante novas turmas tenham dado continuidade ao Programa, embora só tenha crescido a demanda potencial, inclusive com o direito de trabalhadores efetivos, temporários e terceirizados, assegurado pelo Art. 62-A da LDB.

Em relação aos cursos superiores de tecnologia, agora respaldados pela Resolução CES/CNE no 02 e incluídos no rol de reivindicações da CNTE - que, inclusive publicou em 2017 uma excelente proposta de Matriz Curricular, com assessoria do ex-conselheiro Luiz Dourado - vários institutos e universidades foram envolvidos em reuniões com os sindicatos e se dispuseram a estudar sua oferta. A demanda tem crescido muito, em razão do aumento de escolaridade da categoria, mesmo que em algumas redes cursos superiores alheios à profissão valham como fator de progressão na carreira - o que inibe certamente a urgência da continuidade de formação específica dos(as) funcionários(as).

Exemplo significativo ocorre neste 2019 em Mato Grosso. Por iniciativa do Sintep/ MT, 130 municípios do estado apresentaram total de candidatos superior a dez mil pessoas. Esta demanda foi apresentada à Reitoria do IFMT, que no momento se mobiliza para, "em esforço próprio", oferecer os quatro cursos a partir de 2020.

Uma estimativa conservadora, baseada na pesquisa de Mato Grosso, com 3,5 milhões de habitantes, projeta para o Brasil de 210 milhões uma demanda potencial concreta de 
600 mil candidatos a cursos superiores, todos eles(as) funcionários(as) em exercício com ensino médio concluído. Ou seja, para cursos de formação continuada. Quanto à oferta de vagas para cursos de formação inicial, não prescindindo dos bem-sucedidos cursos de nível médio, 60 mil funcionários que se aposentam a cada ano podem-se considerar base para estimativa de demanda de outros 600 mil candidatos nos próximos dez anos.

\section{Por que preservar, expandir e qualificar a formação?}

A leitura do presente artigo e muito mais ainda o estudo dos textos do Parecer CES/ CNE246, de 2016, e da Resolução CES/CNE de 13 de maio do mesmo ano - data histórica da abolição da escravidão no Brasil - nos animam a nos convencermos da perenidade da educação escolar e da presença nela dos educadores não-docentes. Também nos desafiam a assumir esta tarefa hercúlea de formá-los todos(as), preservando as conquistas já reconhecidas internacionalmente dos cursos de nível médio e avançando na formulação de planos de cursos superiores nestas e em futuras novas áreas, conforme já sinalizado pelos sindicatos dos trabalhadores em educação.

Um ano após a publicação da Resolução 02, a CNTE promoveu a construção, com redação final do mesmo conselheiro Luiz Dourado, de uma Sugestão de Matriz Curricular no limite das 2.400 horas previstas, para que as instituições de educação superior, em particular os institutos federais de educação, ciência e tecnologia, possam nela se inspirar ou tomar mesmo como base conceitual e estratégica da oferta dos cursos.

Eles não representam somente a evolução e aperfeiçoamento dos mecanismos de ensino e aprendizagem das competências educativas hoje consideradas não docentes no âmbito das instituições formadoras. Os três anos de tentativas, em diversos estados e cidades, ainda não traduzidos na oferta concreta dos cursos - com exceção de casos isolados em entidades privadas - não significam que eles estão defasados em relação à construção da história.

Estamos pagando um duplo preço: o dos desafios das inovações tecnológicas e pedagógicas e, principalmente, outro de ordem mais profunda e conflitiva - a nova encruzilhada da história do Brasil e da educação mundial. Temos que optar entre uma sociedade construída em estratos que se separam e se hierarquizam, com fraturas profundas ainda no presente, e outra, justa e igualitária, que não nega as diferenças, mas procura superar as desigualdades, até agora reproduzidas e sutilmente "ignoradas", como se só alguns ensinassem e nem todos aprendessem.

A formação sólida e qualificada dos funcionários não é neutra: é posicionamento, é conscientização, é politização, é luta. 
Recebido em: 25/11/2019 e Aprovado em: 23/12/2019

\section{Referências}

ALVES, Gilberto Luís. Azeredo Coutinho. Coleção Educadores, Recife: Fundação Joaquim Nabuco/ Editora Massangana, 2010.

BRASIL. Constituição da República Federativa do Brasil. Edição do Senado Federal, Brasília, 2018.

BRASIL. Lei no 9394, de 20 de dezembro de 1996. Edição Atualizada, Senado Federal, Brasília, 2019.

BRASIL. Conselho Nacional de Educação, Parecer CES/CNE n⿳ํㅜㄹ, de 04 de maio de 2016. Brasília, 2016.

BRASIL. Conselho Nacional de Educação, Resolução CES/CNE 02, de 13 de maio de 2016. Brasília, 2016.

BRASIL. Presidência da República. Decreto 8.752, de 9 de maio de 2016. Brasília, 2016.

BRASIL. Censo Escolar de 2018. INEP, Brasília, 2018.

LEITE, Serafim. História da Companhia de Jesus no Brasil. Edições Loyola: Rio de Janeiro, 1938.

MONLEVADE, João A. C. Funcionários da Educação Básica: educadores profissionais ou servidores descartáveis? Idea Editora: Brasília, 1995.

MONLEVADE, João A. C. Profissionalização ou terceirização? O futuro dos funcionários da educação à luz dos desafios e conquistas do presente. Edição do Autor, Brasília, 2014.

NÓBREGA, Manoel da. Diálogo sobre a Conversão dos Gentios. Lisboa, 1556. 